\title{
Earthen architecture in the Iberian Peninsula: a portrait of vulnerability, sustainability and conservation
}

\author{
Camilla Mileto, Fernando Vegas López-Manzanares, Valentina Cristini* (i) and Lidía García Soriano
}

\begin{abstract}
For more than a decade, a wide range of Spanish case studies, relating especially to rural inner or abandoned sites and areas, have been analysed by the authors as part of different research projects linked with traditional and monumental architecture, conservation strategies and earthen buildings. On one hand the studies have been undertaken in the framework of a project concerning the conservation of rammed earth in the Iberian Peninsula, including criteria, techniques, results and perspectives and, on the other, by a project about the conservation and rehabilitation of traditional earthen architecture in the Iberian Peninsula, providing guidelines and tools for its sustainable intervention. In all cases the researchers' efforts focused on enhancing new perspectives and opportunities for rural earthen buildings, analysing landscapes, contexts, constructive features, decay and problems. The final common aim of this research is to stress these crucial topics to improve tangible or intangible opportunities for conservation strategies.
\end{abstract}

Keywords: Risk analysis, Conservation strategies, Constructive techniques, Preservation tools, RES-TAPIA, SOS-TIERRA

\section{Introduction}

Knowledge of earthen architecture in the Iberian Peninsula is a challenge which has involved the authors of this text over the last decade, aimed at fine-tuning knowledge of monumental and vernacular heritage which use earth as a constructive material in all its forms and interpretations. Two research projects, led by UPV (Universitat Politècnica de València, Spain) RES-TAPIA. Conservation of rammed earth in the Iberian Peninsula. Criteria, techniques, results and perspectives (2011-2013) Ministry of Science and Innovation and SOS-TIERRA. Conservation and rehabilitation of the traditional earthen architecture of the Iberian Peninsula (2015-2018) Spanish Ministry of Economy and Competitiveness have served as a starting point to promote knowledge of this architecture. Detailed databases were used to make possible the main goals of the projects. These were focused on defining guidelines

\footnotetext{
*Correspondence: vacri@cpa.upv.es

Polytechnic University of Valencia, Camino de Vera s/n, 46022 Valencia, Spain
}

for a compatible conservation and rehabilitation of millenary constructive legacy, in both monumental and rural buildings, following respectful and sustainable criteria to avoid alien and standardised solutions, and granting priority to options respecting technical and cultural diversity and lessons in sustainability for the future.

Both projects were carried out by a research team in collaboration with a work group and scientific specialists from different locations. Based on this an extensive inventory was carried out for traditional earthen architecture in the Iberian Peninsula.

These projects also had the collaboration and support of other institutes and research centres, both national and international, as well as international bodies and public administrations.

\section{Objectives: earth as a common denominator in architecture in the Iberian Peninsula}

During this research period the main objective of these projects was to contribute to the valorisation of earthen architecture in the Iberian Peninsula, both monumental 
and vernacular. Traditional materials and techniques were considered respectful means for the promotion of the compatible and sustainable conservation and restoration of this heritage, 'humble' and 'noble' architecture alike (Fig. 1). Some specific objectives were set for this:

- Compilation of information on traditional and monumental earthen architecture in the Iberian Peninsula through different studies and approaches: geographical study, study of constructive techniques and variants, and study of degradation phenomena.

- Extensive compilation and creation of a database for interventions carried out on traditional and monumental earthen heritage in the Iberian Peninsula.

- Updating and application to case studies for the analysis and evaluation of the interventions carried out on monumental and vernacular heritage.

- Drafting guidelines for the conservation and rehabilitation of traditional and monumental earthen architecture.

- Transmission of the knowledge acquired and training of students and professionals through the different actions scheduled (conferences and proceedings, book, exhibition, web...).

\section{Methodology: between vernacular and monumental architecture}

The rigorous methodology followed to meet objectives has been organised into different six main actions:

- State of Art/ step 1. Analysis of the current situation by compiling information and drawing up a database on monumental and traditional earthen architecture in the Iberian Peninsula, as well as interventions carried out.

- State of Art/ step 2. Analysis of the current situation based on a selection of case studies of interventions carried out more frequently following a multidisciplinary methodology (geographical, social and cultural context; analysis of the intervention in terms of conservation, construction and technique used, and of compatibility of materials, structure, energy efficiency, bioclimate and accessibility).

- State of Art/ step 3. Comparison of results with other European and extra European situations, projects and experts in the field.

- Definition of current needs and aspirations to be addressed in the interventions.

- Organisation of a clear set of actions for the conservation and rehabilitation of vernacular and monu-

\section{The conservation of earthen architecture in the Iberian Peninsula}

.

\section{Monumental architecture}

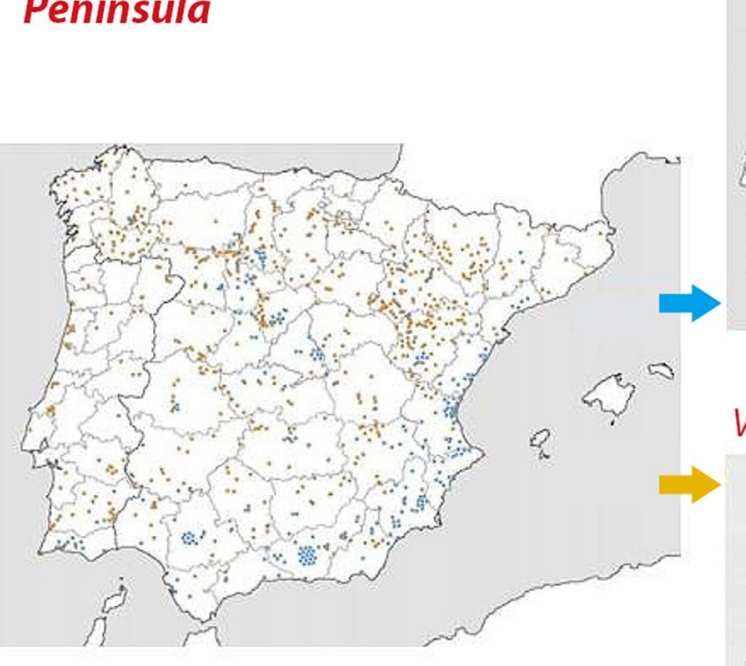

Listed architecture Protected Appreciated Projects Data and documentation Intervention criteria Public funds
Non-listed architecture Non protected Non appreciated Without project Link to functional needs Privately funded

Fig. 1 The objective of these projects was to contribute to the valorisation of earthen architecture in the Iberian Peninsula, both monumental and traditional (Source: RES-TAPIA \& SOS-TIERRA Projects) 
mental traditional earthen architecture in the Iberian Peninsula.

- Dissemination: organisation of different actions for the dissemination and promotion of the main results of the projects.

\section{Study of constructive techniques and variants}

The RES-TAPIA Project studied and analysed different earthen constructive variants found in the Iberian Peninsula. Four major categories were identified in this study (simple rammed earth, both mortar-crusted and adobe-, brick- or stone-faced rammed earth walls, rammed earth walls supplemented at the joints and mixed rammed earth walls). Simple rammed earth walls are made up of a single material, usually earth, although other subvariants incorporate other materials into the mix including lime (stabilised rammed earth), masonry (rammed earth with rubble coffered masonry walls). In certain areas with an abundance of gypsum such as the province of Teruel and surrounding areas it is common to add gypsum to the mix (stabilised-rammed earth).

Crusted or faced rammed earth walls are built incorporating this rendered crust and/or the adobe, brick or stone facing inside the formwork, while being built, so that they already appear with this finish when the formwork is removed. A clear example is lime-crusted rammed earth, which can simply include lime mortar wedges or feature this lime mortar wedges thinly spread between layers throughout the wall panel. Some areas feature gypsum-crusted rammed earth, in which the crust is executed with gypsum, or even other variants like a lime-crust brick-faced rammed earth that is locally called Valencian rammed earth.

The third group, rammed earth walls supplemented at the joints, includes categories where binders, mortars or other elements are added between courses of rammed earth. This group includes rammed earth with mortared joints, rammed earth with gypsum brencas (wave-like additions) and rammed earth with gypsum rafas (pillarlike additions).

The category of mixed rammed earth walls includes those which are partly built bonding stone, brick or adobe buttresses and partly tamping a coffered earth mass between them. Variants are employed based on different factors, such as craftsmen skills, availability of materials and budget. These variants include rammed earth between brick pillars with brick courses, rammed earth between brick pillars with stone courses, rammed earth between ashlar pillars...

Therefore, this work identified variants and subvariants of rammed earth walls, providing a total of 41 different variants of rammed earth walls (Mileto and Vegas 2014).
The SOS-TIERRA Project further studied the constructive variants of rammed earth, expanding the study to other earthen constructive techniques and carried out an analysis of the different earthen constructive techniques found in the Iberian Peninsula. Some, such as the different variants of adobe, rammed earth and half-timber, are still frequently found, while other such as clay lumps or poured earth, are much rarer or have practically disappeared and are found almost exclusively in archaeological contexts.

The different techniques were classified according to how earth was used as a constructive material: monolithic earth walls (rammed earth, poured earth, cob, piled earth); earthen masonry walls or construction by pieces (moulded and hand-moulded adobes, clay lumps, sod, marl), timber and earth walls (half-timber walls, wattleand-daub walls), as well as other uses in earthen vaults, renderings and earthen finishes (paving, rendering, plastering, roofs), earth in auxiliary elements (mortars, infill, reinforcement and smoothing), excavated architecture. Results were obtained from the analysis of the data collected during fieldwork (2460 cases of traditional architecture throughout the Iberian Peninsula). Thus, thanks to the classification of all the data it was possible to establish a complete taxonomy of the most frequently found constructive variants and techniques, as well as a geographical approximation of their location in the peninsula.

This classification showed that rammed earth is the most abundant and widespread constructive technique all over the Iberian Peninsula, except in the Cantabrian corridor. Adobe is also found in much of the territory, most notably in the north half, near to rivers basins, as is half-timber with earth infill.

In addition to the mapping of the different constructive techniques through the analysis of the case studies catalogued, a series of drawings and diagrams of the different variants completed the work started with the previous projects, resulting in a taxonomy identifying 45 rammed earth variants, 39 adobe wall variants which in combination with other variants of walls with sod and marl complete the group of walls built using pieces and 22 variants of rammed earth and timber walls (Fig. 2).

\section{Geographical study: earthen architecture and the territory}

Earthen architecture, both monumental and vernacular, is closely linked to its location, adapting to its surroundings and optimising its resources as concrete constructive solutions. The morphological, climatic and geological properties of the location condition the existence of the different earthen constructive techniques and their specific characteristics and variants. Therefore, this study 


\section{Half timber and wattle and daub}
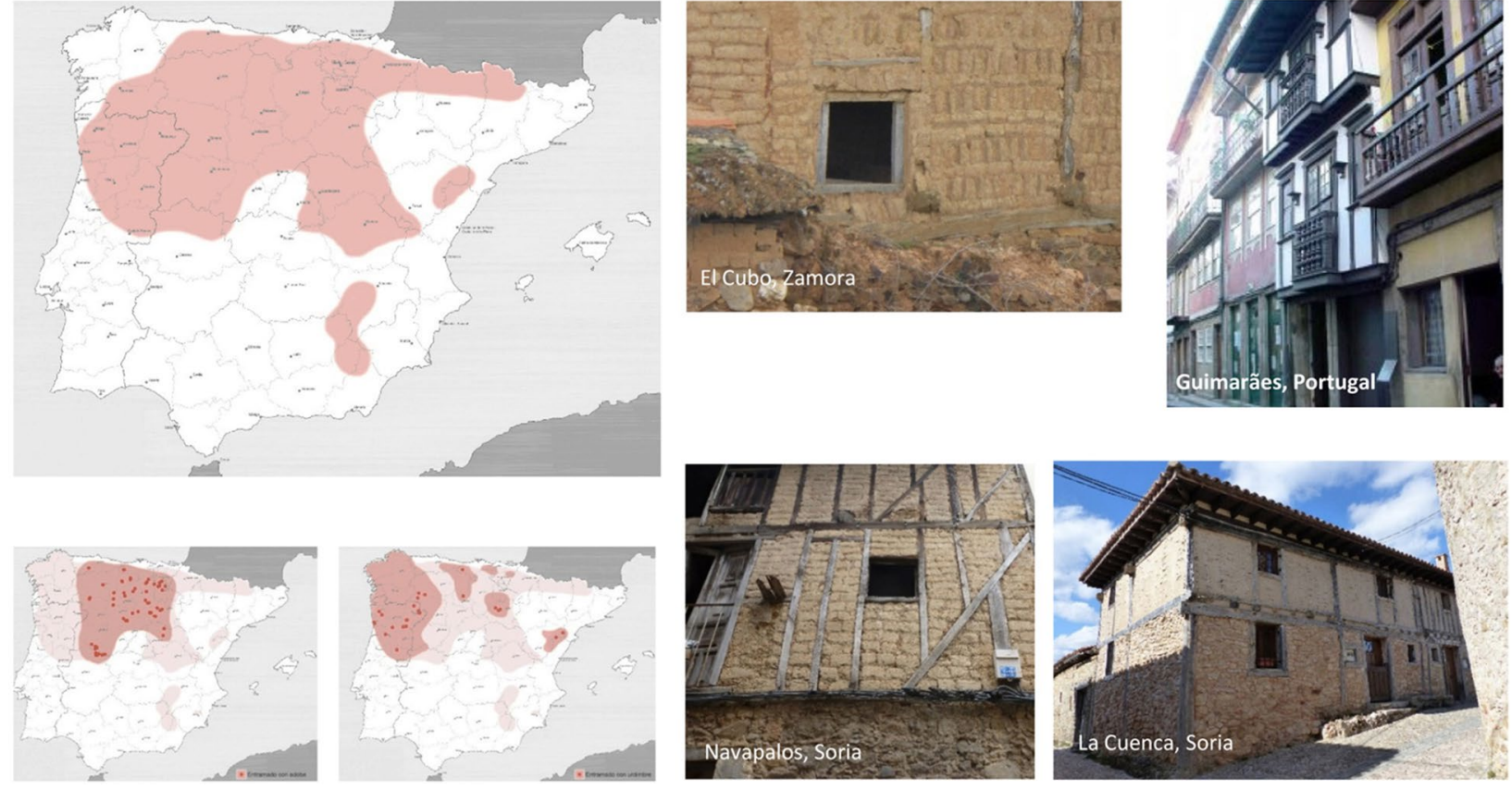

Fig. 2 Example of mapping: different timber walls techniques found in the Iberian Peninsula (Source: RES-TAPIA \& SOS-TIERRA Projects)

aims to establish geographical relations between earthen constructive techniques (grouped into three major categories: rammed earth, adobe and half-timber) and the characteristics of each location, by comparing the location mappings of the different techniques and themed boards. As the themed maps analysed were obtained from official sources (IGN, EAmeT, INE, etc.), they allow work with reliable and contrasted information. Very different aspects of the territory were studied, enabling the analysis of the characteristics of traditional earthen architecture in relation to the different factors to which they correlate in varying degrees. Based on these comparisons information was extracted on the conditions or factors favouring or hindering the adoption of solutions with earthen constructive techniques in traditional architecture in specific locations.

For the study a sample of 618 sites throughout the Iberian Peninsula was taken, identifying one or several earthen construction techniques. Of these 618 sites, rammed earth was recorded in 323, adobe in 293 and half-timber in 178. The geographical studies of individual techniques were carried out by superimposing the geographical, climatic and geological maps on the location of the 618 sites, and establishing the correspondence between these sites and the area in which they are each located on the different themed maps (Fig. 3). From this comparative study it was possible to establish correlations between the techniques and factors favouring or hindering their presence in a specific area. The geographical factors analysed were: landscape, relief and rivers; altimetry; rainfall; and lithology. Despite the various locations and landscapes of earthen architecture, variations are observed in the frequency of landscape, relief and rivers depending on conditions or characteristics.

Five types of landscape were established for analysis: mountain, hill, dry valley, river valley and plain. In terms of altimetry, the Iberian Peninsula is made up of great plains and mountainous regions which directly influence architectural features. Adobe constructions are found at very varied altitudes from the coast (central regions of Portugal or Valencia) to areas of considerable altitude such as the Iberian System (VV.AA. 2005). However, earthen constructions are rarely found in the high altitudes of steep mountainous areas such as the Pyrenees and the Cantabrian mountain range, due to the abundance of stones. The study of geographical areas by rainfall was also important. The presence of water determines the characteristics of configuration and grouping of population nuclei, while at an architectural level medium rainfall influences the configuration of roofs and other constructive elements. The durability of earthen constructions is directly affected by the presence of water, especially when the buildings are not properly protected. Therefore, this type of construction is not 


\section{Influence of geographical factors in the traditional earthen architecture of the Iberian Peninsula}

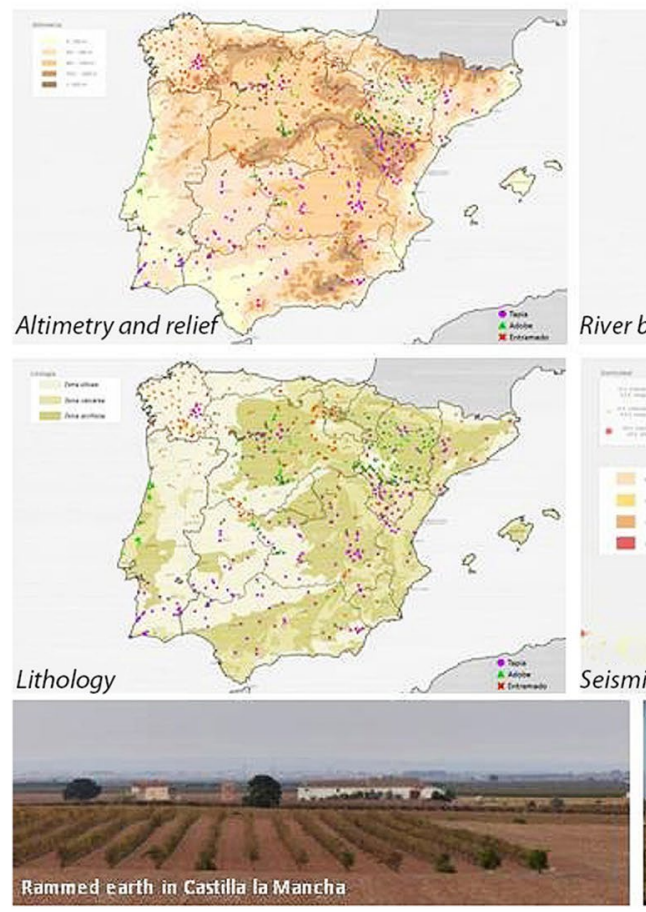

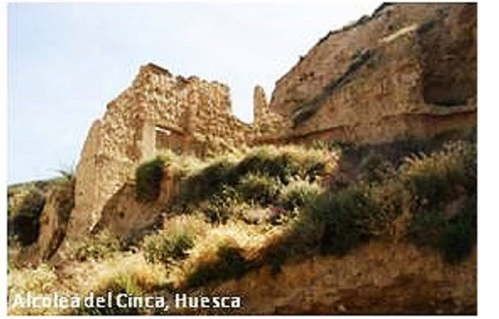
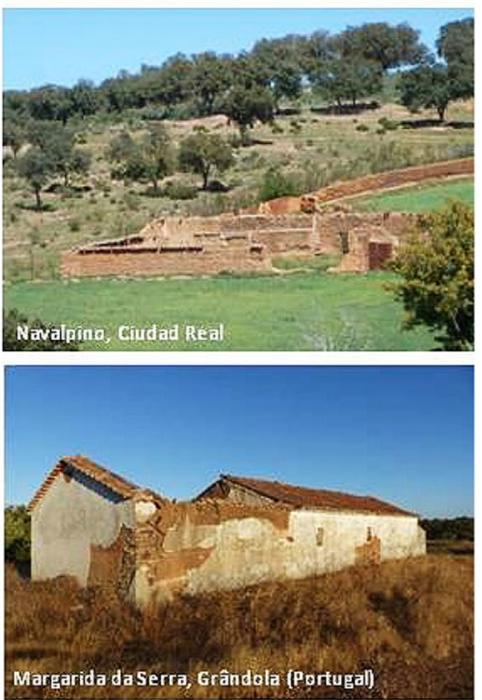

Fig. 3 Mapping of geographical factors that can influence the distribution of earthen constructive techniques (Source: RES-TAPIA \& SOS-TIERRA Projects)

usually found in damper regions such as the north and west of the Iberian Peninsula. This is especially noticeable in the case of rammed earth, as none of the cases analysed were in areas with heavy rainfall. The use of both adobe and half-timber is generally avoided in areas with heavy rainfall. However, some examples have been identified in areas with medium rainfall, including case studies built with adobe in western Portugal and halftimber in the north of the Iberian Peninsula and Sierra de Gredos.

In lithological terms the Iberian Peninsula is divided into two distinct areas: the mostly limey and clayey east and the siliceous west, with the exception of the central western region of Portugal (Correia 2007a, 2007b). Adobe is more closely linked to clayey soil, possibly because the mix requires more clay than rammed earth. Half-timber is also conditioned by the types of infill. An adobe infill is generally more common in clayey regions while fibre infill is more frequently found in siliceous regions such as northern Portugal (Fernandes and Tavares 2016, Correia and Carlos 2015), Galicia and Zamora. Rammed earth is found in equal measures in clayey, calcareous and siliceous areas.
The detailed geographical study of each of these factors showed that earthen construction is found in most of the Iberian Peninsula, except in the north and northwest where very few case studies were found. The siliceous soil and heavy rainfall in these regions are the main reasons for this infrequency. Half-timber is an exception, as it is generally used in cold mountainous areas or areas with heavy rainfall, closely connected to areas with an abundance of timber.

The correlation between the themed mapping and the individual techniques has provided information on the characteristics of the territory, where these specific techniques usually abound, as well as on the factors favouring or limiting their presence (Mileto et al., 2017a, 2017b).

\section{Study of degradation phenomena}

Following the study of the different constructive techniques and variants and the geographical analysis identifying the location of these techniques, a study was carried out on the most characteristic degradation phenomena of each of the techniques and variants. Earthen constructions are highly resistant providing they are protected at the foundations and crowning, possible points of entry 
of water and degradation. In addition, earthen walls should be normally protected from the action of rain with earthen, lime or gypsum mortar (MECD, 2017). The main causes of degradation of an earthen wall are mostly direct constant exposure to the elements (damp, water, wind with suspended particles etc.), occasional structural deficiencies, and biological and anthropic agents such as vegetation, lack of maintenance, abandonment, and the use of unsuitable incompatible materials such as cement, concrete or other non-breathable materials (for example like water vapour impermeable painting systems) which can harm the construction in the mid and long term.

Each phenomenon observed in the building can be identified either as an alteration which does not require intervention or a degradation which must be remedied, paying special attention to the causes in order to prevent the effects from worsening (MECD, 2017). Each of the effects or lesions observed represents a phase of an evolving mechanism which previously took the form of a specific phenomenon in the present and will manifest as another in the future, creating a constantly evolving chain.

Degradation phenomena were analysed depending on the section of wall they occur in (base, wall, crowning and surface- Fig. 4) and the constructive variant of the wall analysed. The RES-TAPIA project marked the start of the analysis of degradation phenomena in this type of wall, while the SOS-TIERRA Project continued with the analysis of degradation phenomena in the other earthen constructive techniques.

In addition to the study of degradation linked to the elements - the main cause of degradation in earthen buildings-other natural factors can also influence the deterioration of earthen constructive elements. This group of lesions-of biological origin-includes all those derived from the presence of living beings around the building such as growing vegetation or the consequences of animal activity on the elements of the wall.

Anthropic agents, that is, any lesions derived directly or indirectly from human actions, are another source of degradation. This group includes the lesions resulting from vandalism on the constructions and others caused by unsuitable maintenance and retrofitting.

A high proportion of abandoned construction was documented so that cases of buildings in ruins or in an advanced state of degradation were frequently observed. The main cause of extreme lesions in these buildings is the action of water, which usually starts to act on the

\section{Phenomena and causes of the mechanisms of decay of earthen architecture}
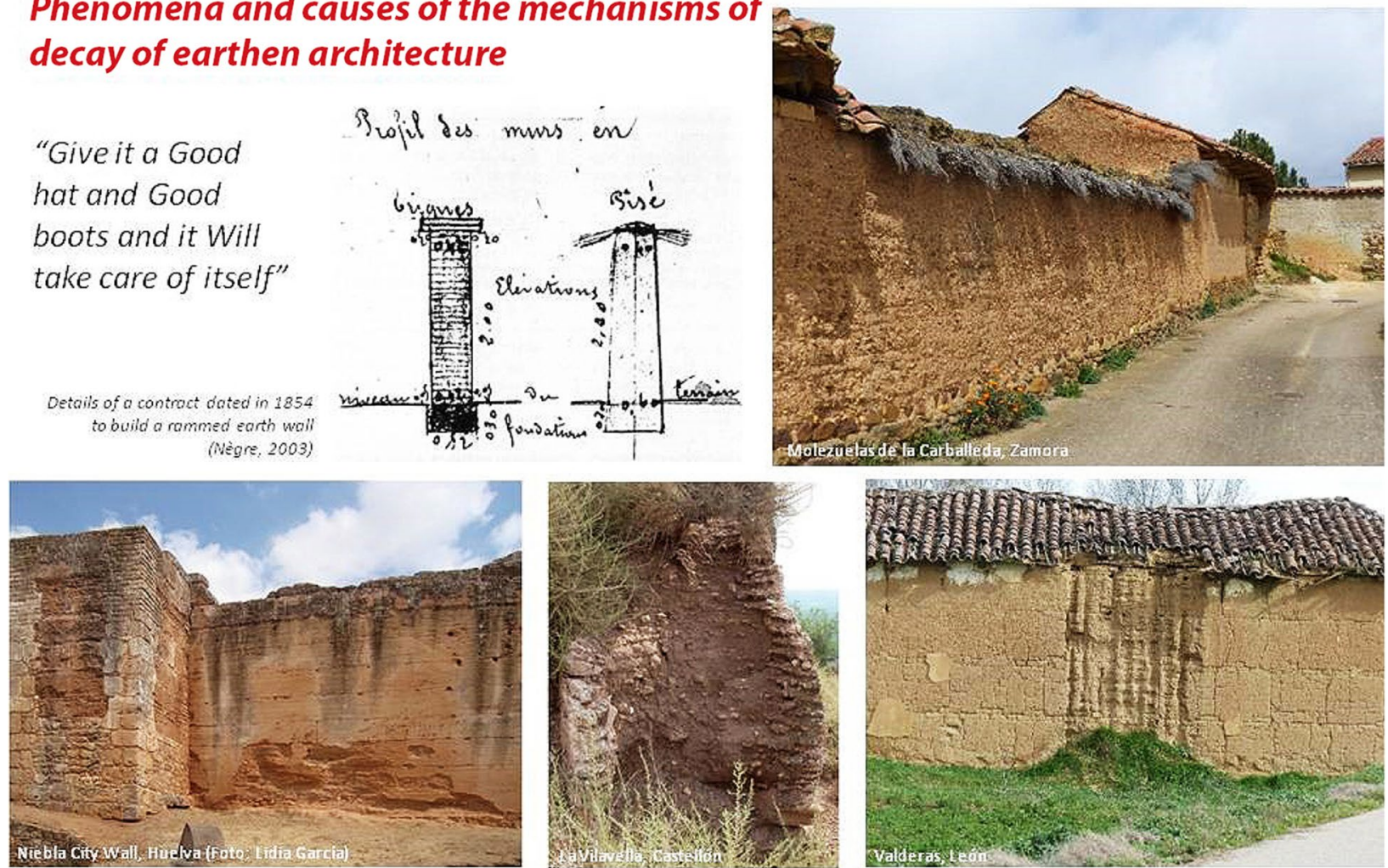

Fig. 4 Analysis of degradation phenomena by constructive technique, variant and wall section affected. Examples of degradations of the rammed earth group affected (Source: RES-TAPIA \& SOS-TIERRA Projects) 
points of the wall lacking protection elements. It is therefore clear that continuous maintenance is the key to the survival of this architecture.

Furthermore, the lesions caused by unsuitable repairs and foreign elements were also catalogued as on occasion maintenance does not always guarantee the suitable conservation of earthen constructions, and unsuitable repairs at times lead to new degradation mechanisms in the building. These unsuitable interventions were recorded in vernacular and monumental buildings.

\section{Study of interventions}

The study of interventions was approached differently in both projects. The RES-TAPIA project studied monumental architecture, that is, buildings with heritage protection, catalogued and appreciated as monuments. The actions and interventions analysed received public funding and extensive documentation was obtained from different archives.

Therefore over 200 interventions carried out on rammed earth buildings in the last 30 years were crossreferenced and analysed, based on crossed parameters. It was concluded that in the early 1980s, interventions were often based mostly on reconstructions, which were more or less general and aimed to restore the monument to its original aesthetic condition. At times this was more restrained, with partial reconstructions, while at others it was more extensive with complete reconstructions, aiming to restore the building to a specific point in its history which was considered of greater architectural splendour and interest. These criteria can be linked to a more historicist line of thinking forgotten in much of Europe but still widespread in the Iberian Peninsula until the late 1980s. In the late 1980s-early 90s criteria more in line with conservation became more prevalent, so that a greater number of interventions based on partial reconstructions of walls and reintegration of missing elements were carried out, while extensive reconstructions were much more infrequent at that point. Over time, the preference for conservation increased and in the 2000s actions for reintegration and the partial reconstruction of volumes were the main proposals favoured.

In terms of the materials used in the interventions it was observed that despite the interest of well-meaning conservation architects to use the original constructive techniques, these techniques were possibly unknown or barely explored in the 1980s so that contemporary materials such as cement were used in the mix to improve the strength of the walls proposed for the intervention.. The use of cement makes these walls less permeable and there is a considerable reduction in material compatibility between the original wall and that of the intervention, usually leading to a series of associated degradation problems (Fig. 4).

Since the late 1980s the cases analysed have shown an increasing use of traditional materials (earth, sand, gravel, masonry, lime) in the new rammed earth mixes, while cement content has generally been reduced although it can still be found in numerous interventions dating from the 1990s. The passing of time has shown the hits and misses of these interventions, and this in turn has influenced the more recent intervention proposals, which have sought to improve technical solutions and respect for pre-existing elements. Therefore, interventions from the 2000s showed an increased use of traditional constructive techniques as the most appropriate options, and other projects appeared in which the aim was to use the original materials, with no additions. This change is the result of increased study and knowledge of the rammed earth technique in recent decades, allowing professionals to use these techniques more precisely, in the knowledge that the use of cement in the mix was in many cases the cause of major degradation in the wall. This caused the appearance of salt efflorescence, which in an advanced state has even caused major material damage, so that the use of cement was reduced (García Soriano 2015).

In contrast, the SOS-TIERRA Project focused on the study of earthen vernacular architecture which was neither catalogued nor protected. In fact this architecture is barely appreciated as built heritage and has therefore undergone spontaneous interventions with no design, generally interventions attempting to respond to the functional needs of owners and paid for with much more limited private funds. These actions are also linked to the lack of specific knowledge on traditional construction, as the current generations missed the transfer of knowledge from previous ones.

The lack of specific regulatory legislation for interventions in traditional buildings, specifically earthen buildings, in most population nuclei has resulted in a wide range of heterogeneous solutions mainly dependent on the needs or the will of owners. The new needs and changes of use, generally made by both the permanent and temporary residents, and the need to repair existing damage generally lead to most interventions. Interventions in monumental architecture are based on projects which follow specific intervention criteria, and techniques are chosen based on these. In most cases the interventions in vernacular architecture lack a deep previous project or specific design analysis and are constrained by necessity and budget.

Therefore, the analysis of interventions in vernacular architecture, rather than analysing the criteria underlying the intervention aims to understand the interventions 
being carried out and the reasons for these, while identifying the dynamics of transformation of this architecture due to the interventions carried out. Therefore, the information recorded in the study record was analysed to extract numerical and percentage data regarding the type of general intervention and the different parts of the building. These data were cross-referenced with the information from other parameters found in the study record, including type and frequency of use in order to establish the relationship which these factors may have with the number or type of interventions executed in the different buildings. The sample consists of 274 case studies, 234 of which $(85 \%)$ have undergone interventions and therefore make up the general sample used in this phase of the work. Among the 234 cases which make up the sample, distinctions were made depending on the constructive technique. Rammed earth accounts for the highest number of cases (107) while adobe and halftimber make up the remaining cases (60 and 67 cases respectively).

The study of interventions and specific intervention criteria as practised in monumental architecture is an arduous task in the case of traditional architecture. The interventions carried out are born in most cases from the need to repair the building to prevent further damage, from their change of use or mere aesthetic transformations (usually with no established criteria), and are greatly conditioned by speedy execution and obtaining materials used. Furthermore, it should be highlighted that in the case of interventions in vernacular architecture the prior condition of most buildings is not known so that prior lesions can only be identified when occasional interventions have been carried out on them or when the initial degradation mechanisms persist despite the interventions. Therefore, intervention criteria had to be simplified and linked to intentionality or prior reflection, and they have been defined as spontaneous intervention or planned intervention.

In general, interventions are not based on a series of conservation or restoration principles and most actions usually only attempt to eliminate problems or lesions as soon as possible, without seeking solutions that are reversible, compatible or distinguishable (Fig. 5). Therefore, the criterion for analysis has focused on studying the type of intervention in relation to the technique and type of material used. The complexity of the sample enabled partial studies to be carried out around different groups of cases with comparable characteristics such as the technique used initially in the construction of the building (rammed earth, adobe or half-timber). These partial analyses allowed to identify and compare the particular aspects of each group. Furthermore, comparative partial analyses were also carried out which were linked to the general level of intervention of the different cases, on the one hand isolating cases with only maintenance and repair intervention, and on the other, cases with a greater level of intervention: restoration, partial rehabilitation, full rehabilitation, expansion and demolition. As update interventions are mostly aesthetic they appear in connection with other types of intervention. Finally, it should be noted that in all cases a general analysis of the type of intervention was carried out for the building, and subsequently the partial interventions were studied in each of the parts of the building specified on the data collection record: walls, base, rendering, openings, flooring and roof.

\section{Proposal of guidelines for intervention}

A proposed intervention must always be the result of a series of factors which combine the needs for conservation and consolidation resulting from a rigorous study and research process on the building, its surroundings and state of conservation. Furthermore, it should consider the possibilities and potential of the values of the heritage itself and its unique aspects, as well as the suitable indications for the use, management and valorisation of this heritage. In order to secure the most reliable results possible in an intervention, these needs, opportunities and suitability should be combined with the respect for general principles which has formed within the field of conservation and restoration, especially attempting to guarantee the material, social and cultural integrity of heritage assets.

Earthen architecture in the Iberian Peninsula presents very heterogeneous types and sizes of buildings, depending on constructive techniques and variants, resources and location, given the state of abandonment and dynamics of transformation affecting the architecture itself. Each case constitutes a unique heritage which should be approached based on its unique character, but following principles and criteria allowing the maximum conservation of the asset in compatibility with the needs for use. These principles and criteria include: respect and conservation of the monumental or vernacular historic building; environmental, socioeconomic and sociocultural sustainability; and the expression of the intervention. It is also important to consider that time continues to advance following the intervention and the restoration carried out becomes part of the building's lifecycle, of the passing of time and of the transformations of the material.

Based on these projects a series of eight codified interventions were proposed as technical solutions which constitute examples of possible specific solutions (Fig. 5). These proposals have focused on earthen walls 

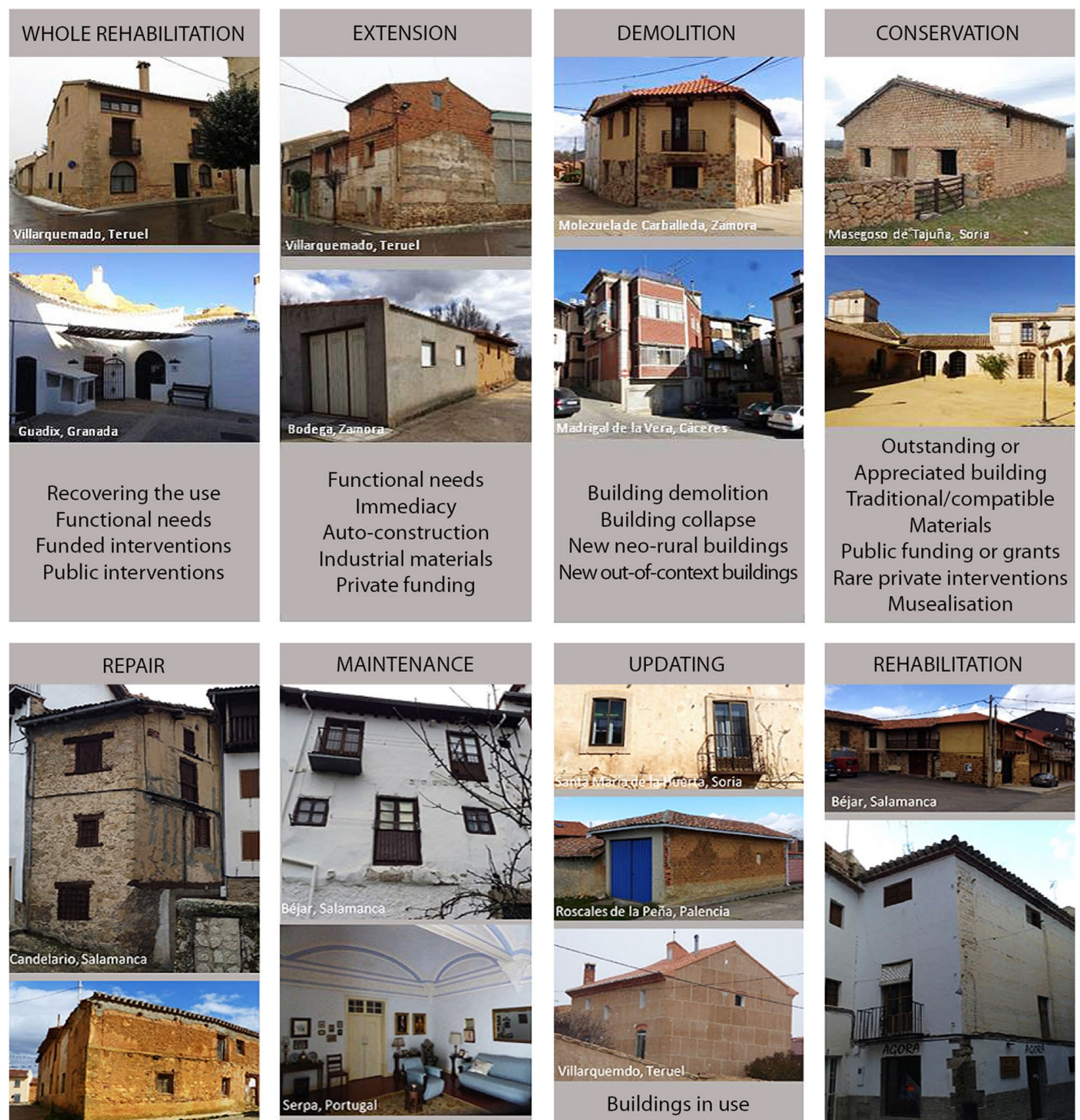

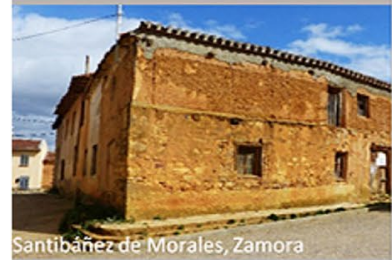

Local repairs

Industrial materials Immediate intervention Private interventions
Continuous care

Compatible materials

Temporary uses

Private interventions
Buildings in use Aesthetic updating Functional needs Energetic efficiency New materials Private interventions
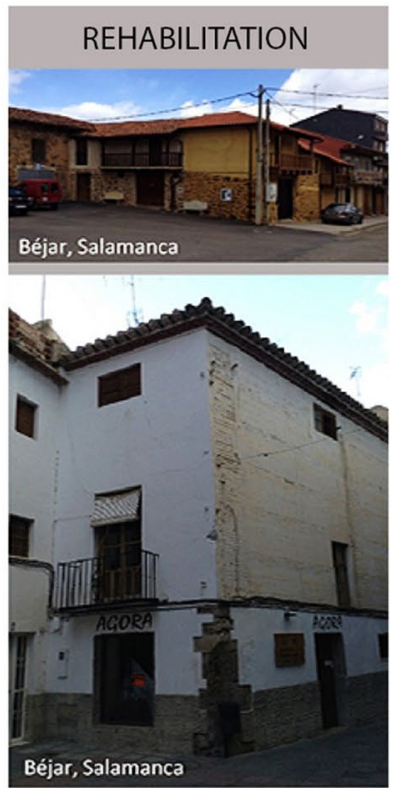

Buildings in use/partial use Functional needs Private interventions

Fig. 5 Examples of interventions and criteria concerning historic earthen architecture. Related to the main 8 actions stressed in the projects (whole rehabilitation, extension, demolition, conservation, repair, maintenance, updating, partial rehabilitation (Source: RES-TAPIA \& SOS-TIERRA Projects)

and their relation or connection with other elements which may directly affect them. Therefore, work which only affects constructive elements (reinforcement of timber elements, joinery, repair of roofs, etc.) was not examined as this was outside the scope of the research objectives. 


\section{Dissemination of the research}

Both projects incorporated several tasks which have contributed to the dissemination of the results obtained (Fig. 6). The dissemination of the RES-TAPIA Project counts on several outcomes.

A reference book for both the Iberian Peninsula and for interventions to be developed in countries with similar problems has been published. The book La restauración de la tapia en la Península Ibérica. Criterios, técnicas, resultados y perspectivas, published by Argumentum and TC Cuadernos, includes texts from numerous experts and main results of the project.

In this frame also a webpage was created for the dissemination and implementation of the results of the project. This website includes the project objectives and the most important results which provide society, especially professionals, companies, researchers, etc., not only with the knowledge acquired, but also with the possibility of carrying out consultations in a specialist forum. An exhibition was organised to showcase the results of the research of this project as well. This work has been exhibited in different Schools of Architecture and Professional Colleges. Finally, another important dissemination action was the Restapia2012 International Conference (held at the UPV, 21-23 June 2012).

The dissemination of the SOS-TIERRA Project also counts on several results. The SOS-TIERRA2017 International Conference was organised (held at the UPV, 14-17 September 2017). In addition, two one-day seminars were organised. The first, 'La restauración de la arquitectura de tierra. Primer seminario SOS-TIERRA' (12-14 November 2015), was organised at the School of Architecture of Valencia, and the second, 'II seminario internacional SOS-TIERRA. La protección y la restauración del patrimonio construido con tierra. Experiencias y oportunidades' (20-22 April 2016), was organised at the School of Architecture of Madrid.

Also in this frame a specific webpage was set up showcasing the main results of the project (cataloguing, case studies, mapping, etc.), and an exhibition was designed to show the final or intermediate results of the research. In parallel, the results of the SOS-TIERRA Project have been published in numerous articles in indexed journals and will finally be published in a coordinated volume, MILETO C., VEGAS F. (eds.), Arquitectura de tierra. Restauración y rehabilitación en la Península Ibérica,

RES-TAPIA. The conservation of rammed earth in the Iberian Peninsula. Criteria, techniques, results and perspectives (2011-2013)

Ministery of Science and Innovation

SOS-TIERRA. Conservation and rehabilitation of the traditional earthen architecture of the Iberian Peninsula (2015-2018) Ministery of Economy and Competitivity
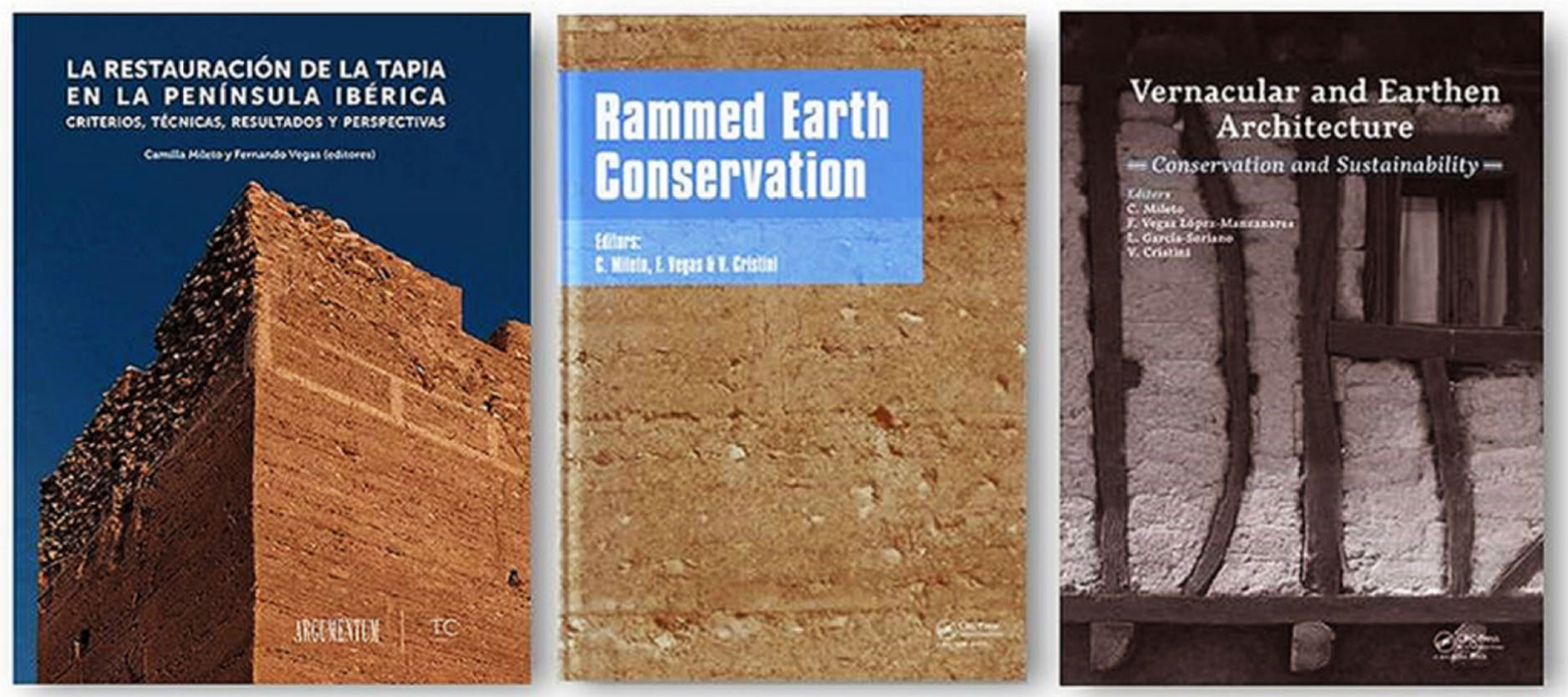

Fig. 6 Some relevant publications resulting from the research projects (Source: RES-TAPIA \& SOS-TIERRA Projects) 
Argumentum-TC (in preparation), with chapters from over 50 national and international authors.

\section{Conclusions and future lines of research}

Earthen architecture, with all its global and rich architectural and constructive manifestations, displays values which have earned it increasing recognition as cultural heritage. The historic and cultural values linked to its presence in space and time serve as proof of human cultural manifestations. These include the economic, constructive and environmental importance of earth as a material; the intangible values linked to the transmission of knowledge and tradition; the aesthetic values resulting from human creativity; and the socioeconomic values linked to the development of social economy. These values, one of the main reasons for the conservation of this heritage, also provide potential inputs to be applied in contemporary interventions and maintenance programs.

However, earthen architecture continues to suffer. Although natural threats constitute a degradation factor, they can always be overcome. Currently, social threats are perhaps the greatest risk factor affecting this architecture, including abandonment, social discrediting, loss of trades and the use of industrial material, and the pressure of tourism development.

The work carried out in both research projects has aimed to build on the knowledge of earthen architectural heritage by defining the scope, value and lessons that this heritage has provided for the present, while proposing guidelines for conservation and rehabilitation interventions.

Following the extensive research, analysis and global cataloguing of this work, both within and outside the Iberian Peninsula, major advances and systematisations have been achieved in terms of knowledge. However, new paths of research have also been identified. The research Project RISK-Terra - Earthen architecture in the Iberian Peninsula: study of natural, social and anthropic risks and strategies to improve resilience, has currently been awarded and funded by the Spanish Ministry of Science and Universities, and proposed as a sort of continuation of the previous research projects. This project is implementing a methodological study of natural risks (floods, landslides, earthquakes, wind, rising temperatures, etc.), social risks (abandonment, social discredit, demographic pressure, tourist development, etc.), and anthropic risks (carelessness and neglect, lack of protection and maintenance, etc.), as well as degradation mechanisms (erosion, loss of materials and parts, collapse, etc.) and transformation dynamics (replacement, use of incompatible techniques and materials, etc.), currently affecting earthen architecture in the Iberian Peninsula.
Abbreviations

UPV: Universitat Politècnica de València (España)/ Polytechnic University of Valencia (Spain); MECD: Ministerio de Educación, Cultura y Deporte (España)/ Spanish Ministry of Education, Culture and Sport.

\section{Acknowledgements}

The research project ResTAPIA 'The conservation of rammed earth in the Iberian Peninsula. Criteria, techniques, results and perspectives' (Ref.: BIA 201018921) was funded by the Spanish Ministry of Science and Innovation. The research project SOStierra 'Restoration and rehabilitation of traditional earthen architecture in the Iberian Peninsula. Guidelines and tools for a sustainable intervention' (Ref.: BIA2014-55924-R) was funded by the Spanish Ministry of Science and Innovation.

The research project RISK-Terra'Earthen architecture in the Iberian Peninsula: study of natural, social and anthropic risks and strategies to improve resilience' (Ref.: RTI2018-095302-B-100) was funded by the Spanish Ministry of Science and Innovation.

Project leaders: Camilla Mileto and Fernando Vegas López-Manzanares.

\section{Authors' contributions}

The individual contributions of authors to the manuscript are the following ones: Chapters 1-2 (V. Cristini), Chapters 3-4 (L. García), Chapter 5-6-7 (C. Mileto), Chapters 8-9 (F. Vegas), Chapters 10 (all authors). The authors read and approved the final manuscript.

\section{Funding}

The research project ResTAPIA 'The conservation of rammed earth in the Iberian Peninsula. Criteria, techniques, results and perspectives' (Ref.: BIA 2010-18921) was funded by the Spanish Ministry of Science and Innovation. The research project SOStierra 'Restoration and rehabilitation of traditional earthen architecture in the Iberian Peninsula. Guidelines and tools for a sustainable intervention' (Ref.: BIA2014-55924-R) was funded by the Spanish Ministry of Science and Innovation.

The research project RISK-Terra 'Earthen architecture in the Iberian Peninsula: study of natural, social and anthropic risks and strategies to improve resilience' (Ref.: RTI2018-095302-B-100) was funded by the Spanish Ministry of Science and Innovation.

Availability of data and materials

Data and references are available in projects webpages (http://www.restapia. es/ and https://sostierra.blogs.upv.es).

\section{Declarations}

\section{Competing interests}

The authors declare that they have no competing interests.

Received: 12 May 2021 Accepted: 16 November 2021

Published online: 30 December 2021

\section{References}

Correia, Mariana. 2007a. Teoría de la conservación y su aplicación a la arquitectura en tierra. Apuntes 20 (2): 202-219.

Correia, Mariana. 2007b. Taipa no Alentejo - Rammed earth in Alentejo. In Cultura sísmica local em Portugal, ed. Mariana Correia and Gilberto Carlos. Lisboa: Argumentum.

Correia, Mariana, and Gilberto Carlos. 2015. Cultura sísmica local em Portugal/ Local seismic culture in Portugal. Lisboa: Argumentum.

Fernandes, Maria, and Alice Tavares. 2016. O Adobe. Lisboa: Argumentum.

García Soriano, L. 2015. "La restauración de la arquitectura de tapia de 1980 a la actualidad a través de los fondos del Ministerio de Cultura y del Ministerio de Fomento del Gobierno de España. Criterios, técnicas y resultados." PhD diss., Universitat Politècnica de València. https://doi.org/10.4995/ Thesis/10251/58607.

MECD. 2017. Proyecto Coremans: Criterios de intervención en la arquitectura de tierra. Madrid: Ministerio de Educación, Cultura y Deporte. 
Mileto, Camilla. Fernando Vegas López-Manzanares, Lidia García-Soriano, and Valentina Cristini. Vernacular and Earthen Architecture: Conservation and Sustainability (Proceedings of SosTierra 2017a, Valencia, Spain, 14-16 September 2017). Londres: Taylor and Francis.

Mileto, Camilla, and Fernando Vegas. 2014. La restauración de la tapia en la Península Ibérica: Criterios, técnicas, resultados y perspectivas. Lisboa: Argumentum / TC Cuadernos.

Mileto, Camilla, Fernando Vegas, Laura Villacampa Crespo, Lidia García-Soriano, and Javier Gómez-Patrocinio. 2017b. "Vernacular earthen architecture in the Iberian Peninsula. First phase of taxonomy and geographical distribution" In Proceedings of Earth USA 2017, Adobe in Action, 102-107.

W.AA. 2005. Arquitectura de terra em Portugal. Lisboa: Argumentum.

\section{Publisher's Note}

Springer Nature remains neutral with regard to jurisdictional claims in published maps and institutional affiliations.

\section{Submit your manuscript to a SpringerOpen ${ }^{\circ}$ journal and benefit from:}

- Convenient online submission

- Rigorous peer review

- Open access: articles freely available online

- High visibility within the field

- Retaining the copyright to your article

Submit your next manuscript at $\mathbf{s p r i n g e r o p e n . c o m ~}$ 